\title{
Colonic Bezoar from Matches as Extremely Rare Cause of a Large Bowel Obstruction
}

\author{
Alina Warmuzińska ${ }^{1}$, Piotr Grzanka1, Iwona Tubek², Sławomir Tubek ${ }^{*}$ and Małgorzata \\ Sobieszczańska ${ }^{4}$ \\ ${ }^{1}$ Department of Radiology, Voivodeship Hopsital, Opole, Poland \\ ${ }^{2}$ Medical Center, Strzelce Opolskie, Poland \\ ${ }^{3}$ Department of Internal Diseases, Voivodeship Hospital, Opole, Poland \\ ${ }^{4}$ Department of Pathophysiology, Medical University, Wrocław, Poland
}

${ }^{*}$ Corresponding author: Sławomir Tubek, Department of Internal Diseases, Voivodeship Hospital, Opole, Oddział Chorób Wewnętrznych, Szpital Wojewódzki W Opolu Sp. z o.o.ul. Katowicka 6445-061 Opole, Polska, Poland, Tel: 774433100, 603781479; Fax: 774433110; E-mail: slawomir.tubek@hipokrates.org

Received: May 10, 2018, Accepted: May 20, 2018, Published: May 22, 2018

Citation: Warmuzińska A, Tubek I, Grzanka P, Tubek S, Sobieszczańska M (2018) Colonic Bezoar from Matches as Extremely Rare Cause of a Large Bowel Obstruction. Med Case Rep Vol.4 No.2:70.

\section{Abstract}

A bezoar is a gastrointestinal mass developed via the accumulation and hardening of undigested or partially digested materials within the digestive tract. While often seen in the stomach, bezoars are rarely observed in the colon. Although many studies have reported that wholegrain foods have a positive effect on intestinal functions because of their high fiber content, a very limited number of case presentations have reported that excessive intake can cause intestinal obstruction.

Keywords: Colonic bezoar; Bowel obstruction; Diarrhea; Fever; Esophagus

\section{Introduction}

Bezoars are masses formed by the concretion of stomach contents or debris within the gastrointestinal tract and are classified based primarily on their content. There are four major types of bezoars. Phytobezoars are the most common type of bezoars and comprise of undigested vegetable material with large amounts of non-digestible fibres such as cellulose, hemicellulose, lignin and fruit tannins. Trichobezoars consist of gastric concretions of hair fibres and are usually found in patients with a history of psychiatric illnesses and in children with intellectual disabilities. Pharmacobezoars consist of medications such as cholestyramine, kayexalate resin, cavafate and antacids, which in bulk will agglutinate. Finally, lactobezoars are milk curds that form secondary to infant formula.

Bezoars are rare and account for only $0.4-4 \%$ of all cases of gastrointestinal obstruction and mainly occur in the stomach or small intestine.1 Intestinal obstruction caused by colonic bezoars is even rarer.

\section{Case Study}

This is a case of a 45-year old woman with recurrent large bowel obstruction caused by biting and swallowing matches (a compulsive behavior) is presented. The patient was hospitalized twice $(2009,2015)$ due to this problem.

Year 2009: A 38-year old women without medical history was admitted to the internal ward due pain in abdomen and rectum, and diarrhea with trace of blood. Upon the admission she did not show any pathological resistance or peritoneum symptoms. The examination of the rectum showed infiltration at level of the anal canal. The CT showed thickening of the sigmoid wall and showed thickening of the rectum's wall, which could indicate a proliferative process with infiltration of perianal fat tissue and fascia perirectal with metastases to perirectal lymphatic nodes. On patient's family's request, the patient was transferred to the surgical ward in another hospital, where patient admitted to matches ingestion habit. The bezoar was recognized, and it was removed endoscopically from sigmoid and rectum.

Year 2015: The same woman (45-years-old) now was admitted to the hospital due the abdominal pain for a week, diarrhea, fever, and weight loss. In the past, she had been treated psychiatrically for her compulsive biting of the matches intensifying during periods of prolonged stress.

The CT was carried out as the patient was suspected to have a relapse of colonic bezoar from matches. In the middle of the abdomen was widened loop of large bowel with large conglomerate of foreign objects (possibly matches). A wall of the large bowel near the found change was thickened. The endoscopic removal of bezoar was unsuccessful. Due to deteriorating stomach symptoms with peritonitis signs, she was subjected to the surgical procedure, during which in the 
removed large bowel many fragments of matches were found. Unfortunately, the operation was followed by the serious complications a septic shock and permanent damage of central nervous system leading to the vegetative state.

\section{Discussion and Conclusion}

A phytobezoar consists of components of indigestible plant material, whose formation is linked to disorders of the digestive tract motility. In the literature, we found some reports of phytobezoars found in the different parts of the digestive tract such as esophagus, stomach, an small intestine. The cases of phytobezoar being a cause of a large bowel obstruction is described very rarely [1-3]. Except the atypical location of the bezoar described in this paper, the material forming the bezoar, i.e., matches, was also unusual. The literature sporadically presents different bezoars that are linked to occupations of the patients, for instance, bezoar made of the wood. What was reported bezoar from wood dust [4], and bezoars from matches and crayons linked to the neuropsychiatric disorder of the patient [5], but none of those patients had bezoar located in the large bowel. What is also specific in the present case is that bezoar was caused by neuropsychiatric disorder manifested by a compulsive swallowing of the matches. Chemicals present in the ignition ingredient of the matches were probably a cause of the local inflammation that subsequently caused peritonitis.

\section{References}

1. Law GW, Lin D, Thomas R (2015) Colonic phytobezoar as a rare cause of large bowel obstruction. BMJ Case Rep 1: 1-5.

2. Yeh J, Saul T, Gingrich A, Wassermann J (2013) Bezoar. 45: 615-616.

3. Kumar B (2011) The mind-body connection: An integrated approach to the diagnosis of colonic trichobezoar. Int J Psychiatry Med 41: 263-270.

4. Pitiacoudis M, Tsaroucha A, Minidis K (2003) Esophageal and small bowel obstruction by occupational bezoar: A report of a case. BMC Gastroenterol 3: 13

5. Marra JG, De Campos Sobrinho AL, De Los Santos Rebaza K (2007) Wood bezoar in the gastrointestinal tract: A case report and literature review. ABCD Arq Bras Cir Dig 20: 293-296. 